OPEN ACCESS

Edited by:

Michael Sauer

University of Natural Resources

and Life Sciences, Vienna, Austria

Reviewed by:

Wolfgang Buckel,

Philipps University of Marburg,

Germany

Ludmila Chistoserdova,

University of Washington,

United States

*Correspondence:

Ivan A. Berg

ivan.berg@uni-muenster.de

Specialty section:

This article was submitted to Microbial Physiology and Metabolism,

a section of the journal

Frontiers in Microbiology

Received: 07 July 2017

Accepted: 21 August 2017 Published: 06 September 2017

Citation:

Boriian F, Johnsen U, Schönheit P

and Berg IA (2017)

Succinyl-CoA:Mesaconate

COA-Transferase

and Mesaconyl-COA Hydratase, Enzymes of the Methylaspartate Cycle

in Haloarcula hispanica.

Front. Microbiol. 8:1683.

doi: 10.3389/fmicb.2017.01683
Succinyl-CoA:Mesaconate CoA-Transferase and \section{Mesaconyl-CoA Hydratase, Enzymes of the Methylaspartate Cycle in Haloarcula hispanica}

\author{
Farshad Borjian 1,2, Ulrike Johnsen ${ }^{3}$, Peter Schönheit ${ }^{3}$ and Ivan A. Berg1,2* \\ ${ }^{1}$ Institut für Molekulare Mikrobiologie und Biotechnologie, Westfälische Wilhelms-Universität Münster, Münster, Germany, \\ ${ }^{2}$ Mikrobiologie, Fakultät für Biologie, Albert-Ludwigs-Universität Freiburg, Freiburg, Germany, ${ }^{3}$ Institut für Allgemeine \\ Mikrobiologie, Christian-Albrechts-Universität zu Kiel, Kiel, Germany
}

Growth on acetate or other acetyl-CoA-generating substrates as a sole source of carbon requires an anaplerotic pathway for the conversion of acetyl-CoA into cellular building blocks. Haloarchaea (class Halobacteria) possess two different anaplerotic pathways, the classical glyoxylate cycle and the novel methylaspartate cycle. The methylaspartate cycle was discovered in Haloarcula spp. and operates in 40\% of sequenced haloarchaea. In this cycle, condensation of one molecule of acetyl-CoA with oxaloacetate gives rise to citrate, which is further converted to 2-oxoglutarate and then to glutamate. The following glutamate rearrangement and deamination lead to mesaconate (methylfumarate) that needs to be activated to mesaconyl-C1-CoA and hydrated to $\beta$-methylmalyl-CoA. The cleavage of $\beta$-methylmalyl-CoA results in the formation of propionyl-CoA and glyoxylate. The carboxylation of propionyl-CoA and the condensation of glyoxylate with another acetyl-CoA molecule give rise to two $\mathrm{C}_{4}$-dicarboxylic acids, thus regenerating the initial acetyl-CoA acceptor and forming malate, its final product. Here we studied two enzymes of the methylaspartate cycle from Haloarcula hispanica, succinyl-CoA:mesaconate CoA-transferase (mesaconate CoA-transferase, Hah_1336) and mesaconyl-CoA hydratase (Hah_1340). Their genes were heterologously expressed in Haloferax volcanii, and the corresponding enzymes were purified and characterized. Mesaconate CoA-transferase was specific for its physiological substrates, mesaconate and succinyl-CoA, and produced only mesaconyl-C1-CoA and no mesaconyl-C4-CoA. Mesaconyl-CoA hydratase had a 3.5fold bias for the physiological substrate, mesaconyl-C1-CoA, compared to mesaconylC4-CoA, and virtually no activity with other tested enoyl-CoA/3-hydroxyacyl-CoA compounds. Our results further prove the functioning of the methylaspartate cycle in haloarchaea and suggest that mesaconate CoA-transferase and mesaconyl-CoA hydratase can be regarded as characteristic enzymes of this cycle.

Keywords: haloarchaea, acetate assimilation, methylaspartate cycle, class III CoA-transferases, enoyl-CoA hydratases 


\section{INTRODUCTION}

The extremely halophilic members of the class Halobacteria, known as haloarchaea, are often the predominant habitants in hypersaline environments (Oren, 2002). To keep the cytoplasmic turgor balanced, haloarchaea primarily accumulate molar concentrations of $\mathrm{KCl}$ in the cytoplasm. Correspondingly, haloarchaeal enzymes are adapted to these conditions and undergo aggregation or denaturation at low salt concentrations (Lanyi, 1974; Dym et al., 1995). Although haloarchaea are quite uniform in cellular structure and inhabit similar environments, they are surprisingly diverse in their metabolic pathways, particularly regarding the carbon metabolism (Falb et al., 2008; Andrei et al., 2012). Haloarchaeal anaplerotic acetate assimilation pathways are the telling example of this diversity.

Anaplerotic pathways enable growth on acetate, fatty acids and other compounds metabolized through acetyl-CoA, allowing formation of all cellular building blocks from this central metabolite. Over $92 \%$ of all sequenced members of haloarchaea possess genes of anaplerotic acetate assimilation pathways (Borjian et al., 2016). About half of haloarchaea use the glyoxylate cycle discovered in Kornberg and Krebs (1957) that functions in all three domains of life (Serrano et al., 1998). Other haloarchaea use the recently described methylaspartate cycle for acetate assimilation (Khomyakova et al., 2011; Borjian et al., 2016, 2017). In this cycle, one molecule of acetyl-CoA and oxaloacetate are converted to glutamate via the reactions of the tricarboxylic acid (TCA) cycle and glutamate dehydrogenase. The key part of the cycle starts with the rearrangement of glutamate into methylaspartate and its following deamination leading to mesaconate (methylfumarate). Mesaconate is then activated to mesaconyl-CoA, hydrated to $\beta$-methylmalyl-CoA and cleaved to propionyl-CoA and glyoxylate. Propionyl-CoA carboxylation leads to methylmalonyl-CoA and subsequently to succinyl-CoA and then (through the TCA cycle) to oxaloacetate, thus closing the cycle. Glyoxylate reacts with another acetyl-CoA molecule yielding malate, the final product of the cycle (Figure 1). In sum, the cycle converts two acetyl-CoA molecules into malate. The functioning of the methylaspartate cycle was experimentally shown in Haloarcula marismortui, Haloarcula hispanica and Natrialba magadii and proposed for many other haloarchaea based on the results of bioinformatic analysis of the distribution of its key enzymes (Khomyakova et al., 2011; Borjian et al., 2016, 2017).

Although the methylaspartate cycle functions merely in haloarchaea, its reactions and intermediates can be found in other metabolic pathways functioning in phylogenetically distant microorganisms (Khomyakova et al., 2011). The only reaction that has been found only in the methylaspartate cycle is succinyl-CoA:mesaconate CoA-transferase (further referred to as mesaconate CoA-transferase or Mct) catalyzing mesaconate activation to mesaconyl-C1-CoA. Although Mct has not been characterized so far, the corresponding gene was identified in haloarchaea (Khomyakova et al., 2011; Borjian et al., 2016). The enzyme belongs to class III CoA-transferases (Heider, 2001).

The further conversion of mesaconyl-C1-CoA formed in the Mct reaction is catalyzed by mesaconyl-CoA hydratase
(Mch) producing $\beta$-methylmalyl-CoA. The enzyme catalyzing this reaction belongs to the family of $(R)$-specific enoyl-CoA hydratases (formerly MaoC family, Teufel et al., 2011). This reaction has previously been identified in two other metabolic pathways: in the autotrophic 3-hydroxypropionate bicycle functioning in Chloroflexus aurantiacus, and in the ethylmalonylCoA pathway of acetate assimilation present in Rhodobacter sphaeroides, Methylobacterium extorquens and many other bacteria (Zarzycki et al., 2008). Although Chloroflexus and Rhodobacter enzymes function in opposite directions under physiological conditions, they share high sequence identity (58 and $73 \%$ sequence identity/similarity) (Zarzycki et al., 2008). In contrast, haloarchaeal Mch does not share any significant sequence similarity to Chloroflexus and Rhodobacter Mch, and its biochemical characterization is of great interest in order to compare catalytic properties of convergently evolved enzymes.

Although the genes for Mct and Mch in haloarchaea are known (hah_1336 and hah_1340 in H. hispanica, respectively), all our attempts to heterologously produce the corresponding enzymes in Escherichia coli resulted in the synthesis of insoluble proteins, and their reactivation was unsuccessful (Khomyakova et al., 2011). In this work, we produced H. hispanica enzymes in another haloarchaeon, Haloferax volcanii, which lacks the methylaspartate cycle genes and uses the glyoxylate cycle for acetate assimilation. The following purification and characterization of these proteins confirmed their functions and closed the last gaps in characterization of the methylaspartate cycle enzymes.

\section{MATERIALS AND METHODS}

\section{Materials}

Chemicals were obtained from Fluka (Neu-Ulm, Germany), Sigma-Aldrich (Deisenhofen, Germany), Merck (Darmstadt, Germany), Serva (Heidelberg, Germany), or Roth (Karlsruhe, Germany). Biochemicals were from Roche Diagnostics (Mannheim, Germany), AppliChem (Darmstadt, Germany), or Gerbu (Craiberg, Germany). Materials for cloning were purchased from New England Biolabs (Frankfurt, Germany), Novagen (Schwalbach, Germany), Genaxxon Bioscience GmbH (Biberach, Germany), MWG Biotech AG (Ebersberg, Germany), Biomers (Ulm, Germany), or Qiagen (Hilden, Germany). Primers were synthesized by Sigma-Aldrich (Taufkirchen, Germany). Materials and equipment for protein purification were obtained from GE Healthcare (Freiburg, Germany) or Millipore (Eschborn, Germany).

\section{Microbial Strains and Culture Conditions}

Haloferax volcanii strain H1209 was used for the heterologous expression of H. hispanica proteins (Allers et al., 2010). This strain was transformed with pTA963 vector carrying hah_1336 $(m c t)$ or hah_1340 (mch) under the control of the inducible tryptophan promoter. Expression was performed in complex medium containing the respective compounds according to Allers et al. (2010). E. coli strain DH5 $\alpha$ (NEB) was grown at $37^{\circ} \mathrm{C}$ in lysogeny broth (LB) medium (Sambrook et al., 1989). 


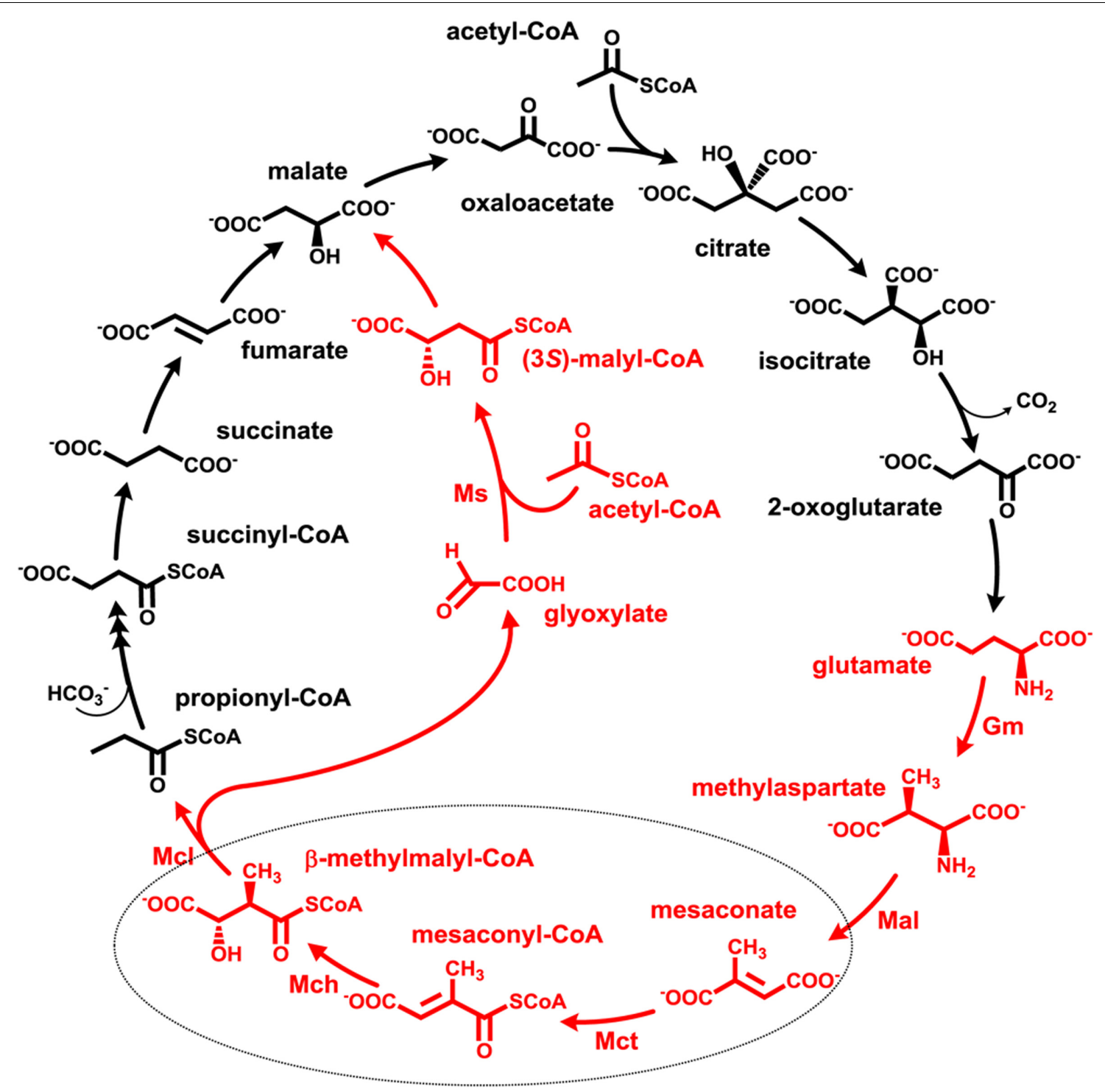

FIGURE 1 | The methylaspartate cycle as studied in $\mathrm{H}$. hispanica. The characteristic intermediates of the cycle are shown in red. Gm, glutamate mutase; Mal, methylaspartate ammonia lyase; Mct, succinyl-CoA:mesaconate CoA-transferase; Mch, mesaconyl-CoA hydratase; Mcl, $\beta$-methylmalyl-CoA lyase; Ms, apparent malate synthase.

If necessary, ampicillin was added to the cultures to a final concentration of $0.1 \mathrm{mg} / \mathrm{ml}$.

\section{CoA-Esters}

$(R, S)$-3-Hydroxy-3-methylglutaryl-CoA and $\beta$-methylcrotonylCoA were obtained from Sigma-Aldrich. Acetyl-CoA, propionyl-CoA and itaconyl-CoA (mixture of itaconyl-C1-CoA and itaconyl-C4-CoA) were synthesized from their anhydrides and acetoacetyl-CoA from diketene by the method of Simon and Shemin (1953). Itaconyl-C1-CoA and itaconyl-C4-CoA were purified from the mixture of itaconyl-C1-CoA and itaconylC4-CoA using high-performance liquid chromatography (HPLC) (Sasikaran et al., 2014). $\beta$-Methylmalyl-CoA, (S)-malylCoA and $(S)$-citramalyl-CoA were synthesized enzymatically with recombinant (S)-malyl-CoA/ $\beta$-methylmalyl-CoA/(S)citramalyl-CoA lyase from Chloroflexus aurantiacus (Zarzycki et al., 2009), as described previously (Sasikaran et al., 2014). Crotonyl-CoA, 3-hydroxybutyryl-CoA and a mixture of the mesaconyl-C1-CoA and the mesaconyl-C4-CoA were synthesized chemically from the free acid by the mixed anhydride method of Stadtman (1957). From this mixture, mesaconyl-C1-CoA and mesaconyl-C4-CoA were purified using HPLC (Zarzycki et al., 2009). The dry powders of the CoA-esters were stored at $-20^{\circ} \mathrm{C}$.

\section{Preparation of Cell Extracts}

Cell extracts were prepared under oxic conditions using an ultrasonic homogenizer Bandelin UW mini20 
(BANDELIN Electronic GmbH \& Co, Berlin, Germany). Cells (100 mg) were suspended in $0.2 \mathrm{ml}$ of $50 \mathrm{mM}$ Tris(hydroxymethyl)aminomethane/HCl, $\mathrm{pH} \quad 7.8$, including $2 \mathrm{M} \mathrm{KCl}$ and $0.1 \mathrm{mg} \mathrm{ml}^{-1}$ DNase I in $1.5 \mathrm{ml}$ Eppendorf vials. Cell suspensions were sonicated $3 \times 60 \mathrm{~s}$ ( $0.5 \mathrm{~s}$ pulse, $70 \%)$ on ice, followed by a centrifugation step $\left(14,000 \mathrm{~g}, 4^{\circ} \mathrm{C}, 20 \mathrm{~min}\right)$, and the supernatants (cell extracts) were used for enzyme assays.

\section{Enzyme Assays}

All enzyme assays were performed at $37^{\circ} \mathrm{C}$. One unit corresponds to $1 \mu \mathrm{mol}$ substrate converted per minute.

Mesaconate CoA-transferase activity was measured by ultraperformance liquid chromatography (UPLC) as succinyl-CoAand mesaconate-dependent formation of mesaconyl-CoA. The reaction mixture contained $100 \mathrm{mM}$ Tris/ $\mathrm{HCl}(\mathrm{pH} 7.8), 3 \mathrm{M} \mathrm{KCl}$, $5 \mathrm{mM} \mathrm{MgCl}_{2}, 1 \mathrm{mM}$ succinyl-CoA, and cell extract or enzyme. The reaction was started by the addition of $10 \mathrm{mM}$ mesaconate. After appropriate time intervals, $25 \mu \mathrm{l}$ of the assay mixture was transferred to ice, and the reaction was stopped by addition of $10 \mu \mathrm{l}$ of $2 \mathrm{M} \mathrm{HCl} / 10 \%$ acetonitrile. Protein was removed by centrifugation, and the samples were analyzed by reverse-phase (RP) $\mathrm{C}_{18}$ UPLC, as described previously (Sasikaran et al., 2014).

Mesaconyl-CoA hydratase was measured in either forward or reverse direction by detecting the formation of $\beta$-methylmalylCoA from mesaconyl-C1-CoA or mesaconyl-C1-CoA from $\beta$-methylmalyl-CoA. For the measurements in the forward direction, the reaction mixture contained $100 \mathrm{mM}$ Tris $/ \mathrm{HCl}$ ( $\mathrm{pH}$ 7.8), $3 \mathrm{M} \mathrm{KCl}, 5 \mathrm{mM} \mathrm{MgCl}_{2}, 1 \mathrm{mM}$ mesaconyl-C1$\mathrm{CoA}$, and cell extract. For the measurements in the reverse direction, mesaconyl-C1-CoA was replaced by $\beta$-methylmalylCoA $(0.5 \mathrm{mM})$. The reaction was started by the addition of CoA-ester and stopped, as described above. The products were analyzed by RP-C 18 UPLC (Sasikaran et al., 2014).

\section{Determination of $K_{m}$ and $V_{\max }$ Values for Recombinant Mesaconate CoA-Transferase and Mesaconyl-CoA Hydratase}

$K_{m}$ values for the mesaconate CoA-transferase for succinyl-CoA were measured in the reaction mixture containing $100 \mathrm{mM}$ Tris/ $\mathrm{HCl}$ ( $\mathrm{pH}$ 7.8), $3 \mathrm{M} \mathrm{KCl,} 5 \mathrm{mM} \mathrm{MgCl} 2,10 \mathrm{mM}$ mesaconate, 0.02-5 mM succinyl-CoA, and enzyme. $K_{m}$ value assays for methylsuccinate and mesaconate where performed, using $1 \mathrm{mM}$ and/or $5 \mathrm{mM}$ succinyl-CoA and $0.1-10 \mathrm{mM}$ of the organic acids. $K_{m}$ value assays for glutarate and acrylate where performed, using $1 \mathrm{mM}$ succinyl-CoA and 1-100 mM of the organic acids. Assays for $1 \mathrm{mM}$ acetyl-CoA, propionyl-CoA, butyryl-CoA and acetoacetyl-CoA as $\mathrm{CoA}$ donor or $10 \mathrm{mM}$ methylmalonate, crotonate, acetoacetate, itaconate, acetate, propionate, butyrate, citrate, citramalate, 2-hydroxyglutarate, citraconate, fumarate, malate and methacrylate as CoA acceptor were performed as described above, using $10 \mathrm{mM}$ mesaconate as CoA acceptor or $1 \mathrm{mM}$ succinyl-CoA as CoA donor, respectively.

$K_{m}$ values for the mesaconyl-CoA hydratase were measured in the reaction mixture containing $100 \mathrm{mM}$ Tris/ $\mathrm{HCl}(\mathrm{pH}$ 7.8), $3 \mathrm{M} \mathrm{KCl}, 5 \mathrm{mM} \mathrm{MgCl}$, 0.02-2 mM $\beta$-methylmalyl-CoA,
0.05-5 mM mesaconyl-C1-CoA, 0.02-2 mM mesaconyl-C4-CoA, 0.05-5 mM (S)-citramalyl-CoA and 0.02-2 mM (S)-malyl-CoA. For itaconyl-C1-CoA, itaconyl-C4-CoA, $(R, S)$-3-hydroxy-3methylglutaryl-CoA, $\beta$-methylcrotonyl-CoA, crotonyl-CoA and 3-hydroxybutyryl-CoA, $1 \mathrm{mM}$ CoA ester was applied.

\section{Cloning of $\boldsymbol{H}$. hispanica Genes in $\boldsymbol{E}$. coli}

Standard protocols were used for purification, cloning, transformation, and amplification of DNA (Ausubel et al., 1987). Plasmid DNA was isolated with the QIAprep Spin Miniprep Kit (Qiagen).

Primers and restriction enzymes used for the cloning of the $m c h$ and $m c t$ genes of $H$. hispanica are listed in Supplementary Table S1. The genes were amplified using Q5 polymerase (NEB). PCR conditions were as follows: 35 cycles of 30 -s denaturation at $98^{\circ} \mathrm{C}, 30$-s primer annealing and 1 min elongation at $72^{\circ} \mathrm{C}$. The PCR products were treated with NdeI and BamHI, and the $m c t$ and $m c h$ genes were separately ligated into the expression vector pTA963 containing a sequence encoding an $\mathrm{N}$-terminal $\mathrm{His}_{6}$-tag. The plasmids were transformed into E. coli $\mathrm{DH} 5 \alpha$ for amplification, followed by their purification and sequencing.

\section{Heterologous Expression of mct and mch from $H$. hispanica in $H$. volcanii}

The amplified pTA963-mct and pTA963-mch were used to transform the $H$. volcanii $\mathrm{H} 1209$ cells. Growth of transformed cells was performed in Hv-YPC broth (Allers et al., 2010) and the respective cells were used to inoculated $800 \mathrm{ml}$ of Hv-YPC broth. Expression was started (optical density of $\sim 0.4$ at $600 \mathrm{~nm}$ ) by the addition of $2 \mathrm{mM}$ tryptophan at $42^{\circ} \mathrm{C}$. After $18 \mathrm{~h}$ of further growth, cells were harvested by centrifugation.

\section{Purification of Recombinant Enzymes}

Frozen cells of the above mentioned expressions were suspended in a double volume of $50 \mathrm{mM}$ Tris/ $\mathrm{HCl}(\mathrm{pH}$ 8.2) containing $2 \mathrm{M} \mathrm{KCl}, 5 \mathrm{mM}$ imidazole and $0.1 \mathrm{mg} \mathrm{ml}^{-1}$ DNase I. The suspensions were passed twice through a chilled French pressure cell at $137 \mathrm{MPa}$, and the cell lysates were centrifuged for $1 \mathrm{~h}$ $\left(100,000 \mathrm{~g} ; 4^{\circ} \mathrm{C}\right)$. The supernatant was applied at a flow rate of $0.5 \mathrm{ml} \mathrm{min}^{-1}$ to a $1-\mathrm{ml}$ Protino Ni-NTA column (MachereyNagel) that had been equilibrated with $50 \mathrm{mM}$ Tris/ $\mathrm{HCl}(\mathrm{pH}$ 8.2) containing $2 \mathrm{M} \mathrm{KCl}$ and $5 \mathrm{mM}$ imidazole. The column was washed with the same buffer containing $30 \mathrm{mM}$ imidazole at a flow rate of $0.5 \mathrm{ml} \mathrm{min} \mathrm{m}^{-1}$ to elute undesired protein. The recombinant His $_{6}$-tagged enzymes were eluted with the same buffer containing $150 \mathrm{mM}$ imidazole. The enzymes were concentrated using 10K Microsep Advance Centrifugal Device (Pall Corporation, Dreieich, Germany) and stored at $4^{\circ} \mathrm{C}$.

Gel filtration chromatography was used for further purification of Mct and Mch and to estimate their native molecular mass. A 24-ml Superdex 200 Increase 10/300 GL column (GE Healthcare) was equilibrated and run with $50 \mathrm{mM}$ Tris/ $\mathrm{HCl}$ ( $\mathrm{pH} 8.0$ ) containing $2 \mathrm{M} \mathrm{KCl}$ with a flow rate of $0.75 \mathrm{ml}$ $\min ^{-1}$. The column was calibrated with alcohol dehydrogenase $(150 \mathrm{kDa})$, bovine serum albumin $(66 \mathrm{kDa})$, carbonic anhydrase $(29 \mathrm{kDa})$, and cytochrome $c(12.4 \mathrm{kDa})$. 


\section{Database Search and Phylogenetic Analysis}

Query sequences were obtained from the National Center for Biotechnology Information (NCBI) database. The BLAST searches were performed via NCBI BLASTP server ${ }^{1}$ (Altschul et al., 1990). The amino acid sequences of Mct (hah_1336) and Mch (hah_1340) from $H$. hispanica were used as queries. The E-value cutoff was set at 1e-100 for Mct and 1e-20 for Mch. The amino acid sequences were aligned with sequences from GenBank using CLUSTALW (Thompson et al., 1994) implemented within BioEdit software ${ }^{2}$. The phylogenetic trees were reconstructed using a maximum likelihood algorithm (Felsenstein, 1981) implemented in MEGA6 software (Tamura et al., 2013). 1000 bootstrap replications were conducted to evaluate the reliability of the reconstructed trees. The GenBank accession numbers for the sequences used for the construction of the phylogenetic trees are listed in Supplementary Tables S2, S3.

\section{Other Methods}

Apparent $K_{m}$ and $V_{\max }$ values were calculated using GraphPad Prism4 software. CoA and CoA-esters were identified and quantified by UPLC using an $\mathrm{RP}^{-\mathrm{C}_{18}}$ column $\left(\mathrm{BEH} \mathrm{C}_{18}\right.$, $1.7 \mu \mathrm{m}, 2.1 \times 100 \mathrm{~mm}$ column, Waters), as described in (Sasikaran et al., 2014). The identification of the CoAesters was based on co-chromatography with standards and analysis of the UV spectra and retention times (Sasikaran et al., 2014). The UV spectra of mesaconyl-C1-CoA and mesaconyl-C4-CoA are shown in (Zarzycki et al., 2009), of itaconyl-C1-CoA and itaconyl-C4-CoA in Supplementary Figure S1. Protein concentration was determined by two methods. For cell extracts, we used the Bradford method (Bradford, 1976) with bovine serum albumin as a standard. For purified enzymes, protein concentration was determined photometrically (Nanodrop 1000, Peqlab) by measuring an adsorption at $280 \mathrm{~nm}$. Extinction coefficients of the enzymes were calculated from their primary amino acid sequences (Gill and von Hippel, 1989) using the ProtParam online tool ${ }^{3}$. The structural analyses of the enzymes were performed with ProtParam tool in the ExPASy database. DNA sequence determination was performed by GATC Biotech (Constance, Germany). Sodium dodecyl sulfate-polyacrylamide gel electrophoresis (SDSPAGE) (12.5\%) was performed as described by Laemmli (1970). An unstained protein MW marker (Thermo) was used as molecular mass standard (14.4-116 kDa). Proteins were visualized by Coomassie blue staining (Zehr et al., 1989).

Analysis of SDS-gel protein bands was performed by protein mass spectrometry (MS) as following: the MS raw data files were uploaded into the MaxQuant software version 1.4.1.2 (Cox and Mann, 2008), which performs peak detection, generates peak lists of mass error corrected peptides and performs database searches. For the identification of Hah_1336 and Hah_1340, H. hispanica and $H$. volcanii database including the corresponding genes

\footnotetext{
${ }^{1}$ http://www.ncbi.nlm.nih.gov/BLAST/

${ }^{2}$ http://www.mbio.ncsu.edu/BioEdit/bioedit.html

${ }^{3}$ http://web.expasy.org/protparam/
}

from $H$. hispanica was employed, and methionine oxidation and protein amino-terminal acetylation were set as variable modifications. Three miss-cleavages were allowed, enzyme specificity was trypsin/P, and the MS/MS tolerance was set to $0.5 \mathrm{Da}$. The average mass precision of identified peptides was in general less than $1 \mathrm{ppm}$ after recalibration. Peptide lists were further used by MaxQuant software to identify and relatively quantify proteins using the following parameters: peptide, and protein false discovery rates (FDR) were set to 0.01 , maximum peptide posterior error probability (PEP) was set to 0.1 , minimum peptide length was set to 6 , minimum number peptides for identification and quantitation of proteins was set to two, one of which must be unique, and identified proteins have been requantified.

\section{RESULTS}

\section{Cloning and Expression of the Genes for Mesaconate CoA-Transferase (mct) and Mesaconyl-CoA Hydratase (mch)}

The 1.19-kb mct gene (396 amino acids, predicted molecular mass $43 \mathrm{kDa}$ ) and the $1.07-\mathrm{kb}$ mch gene (358 amino acids, predicted molecular mass $40 \mathrm{kDa}$ ) from $H$. hispanica were cloned to the expression vector pTA-963 containing a tryptophaninducible promotor p.tnaA, resulting in the plasmids pTA963-mct and pTA-963-mch, respectively. Since these plasmids encode proteins with $\mathrm{N}$-terminal $\mathrm{His}_{6}$-tag, their molecular mass is altered by about $+1 \mathrm{kDa}$. Both plasmids were first transformed into Haloferax volcanii $\mathrm{H} 1209$ for heterologous expression. The heterologously produced enzymes were soluble, as is seen from the results of the detection of Mct/Mch activity in cell extracts of the corresponding $H$. volcanii strains (data not shown).

\section{Purification of Recombinant Mct and Mch}

Both enzymes were purified in a similar manner (Table $\mathbf{1}$ ). After the $100,000 \times g$ centrifugation step, the cell extracts were applied onto a Ni-sepharose affinity column. The active fractions were further purified using gel filtration chromatography, and the concentrated fractions with Mct or Mch activity were used for characterization. Both enzymes could be stored at $+4^{\circ} \mathrm{C}$ for 1 week without loss of activity. However, 3weeks-incubation resulted in the loss of $20-30 \%$ activity. Freezing of the proteins at $-20^{\circ} \mathrm{C}$ led to enzyme inactivation (less than $1 \%$ activity remained). The molecular masses of recombinant Mct and Mch in SDS gel (48 and $43 \mathrm{kDa}$, respectively) were close to the predicted values (44 and $41 \mathrm{kDa}$, respectively; Figure 2). The identity of the purified recombinant proteins was confirmed using gel digestion by trypsin followed by LC-MS/MS (Mct: 28 matched peptides with posterior error probability 0; Mch: 32 matched peptides with posterior error probability 0) (Supplementary Tables S4, S5). Analytical gel filtration indicated a molecular mass of native recombinant enzymes of 71 and $86 \mathrm{kDa}$ for Mct and Mch, 
TABLE 1 | Purification of recombinant mesaconate CoA-transferase (Mct) and mesaconyl-CoA hydratase (Mch) from H. hispanica.

\begin{tabular}{|c|c|c|c|c|c|c|}
\hline Enzyme & Purification step & Total protein (mg) & Total activity (U) & Specific activity $\left(\mathrm{U} \mathrm{mg}^{-1}\right)$ & Enrichment factor & Yield (\%) \\
\hline \multirow[t]{3}{*}{ Mct } & Cell extract & 66.8 & 7.05 & 0.105 & 1 & 100 \\
\hline & Nickel column & 0.94 & 6.6 & 7.02 & 67 & 93 \\
\hline & Gel filtration & 0.13 & 2.19 & 16.9 & 161 & 31 \\
\hline \multirow[t]{3}{*}{ Mch } & Cell extract & 290 & 107 & 0.368 & 1 & 100 \\
\hline & Nickel column & 0.80 & 96.1 & 120 & 327 & 90 \\
\hline & Gel filtration & 0.070 & 11.01 & 157 & 427 & 10.3 \\
\hline
\end{tabular}

Activity was tested with $1 \mathrm{mM}$ succinyl-CoA and $10 \mathrm{mM}$ mesaconate (Mct) and with $0.5 \mathrm{mM} \beta$-methylmalyl-CoA (Mch).

A

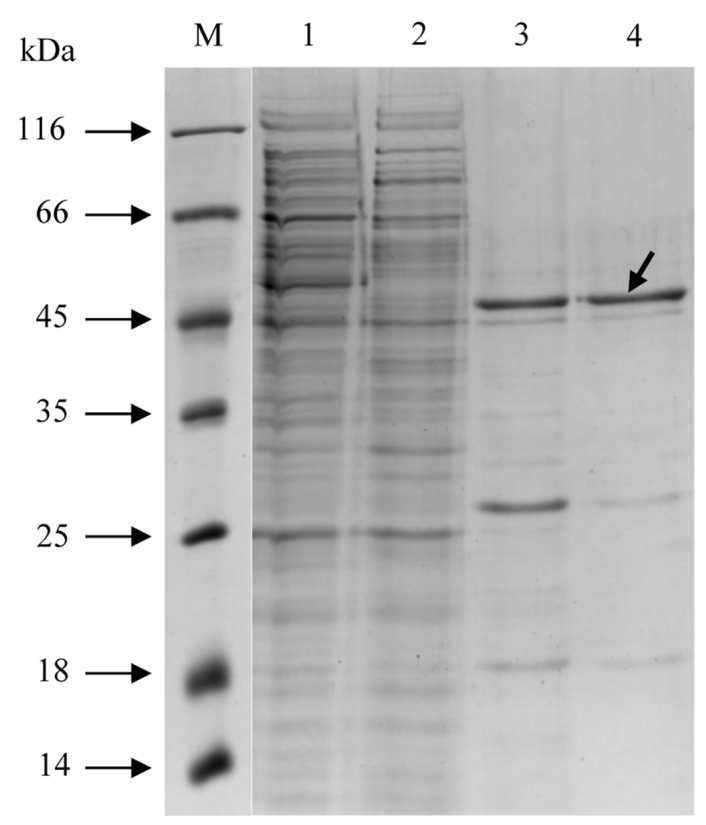

B

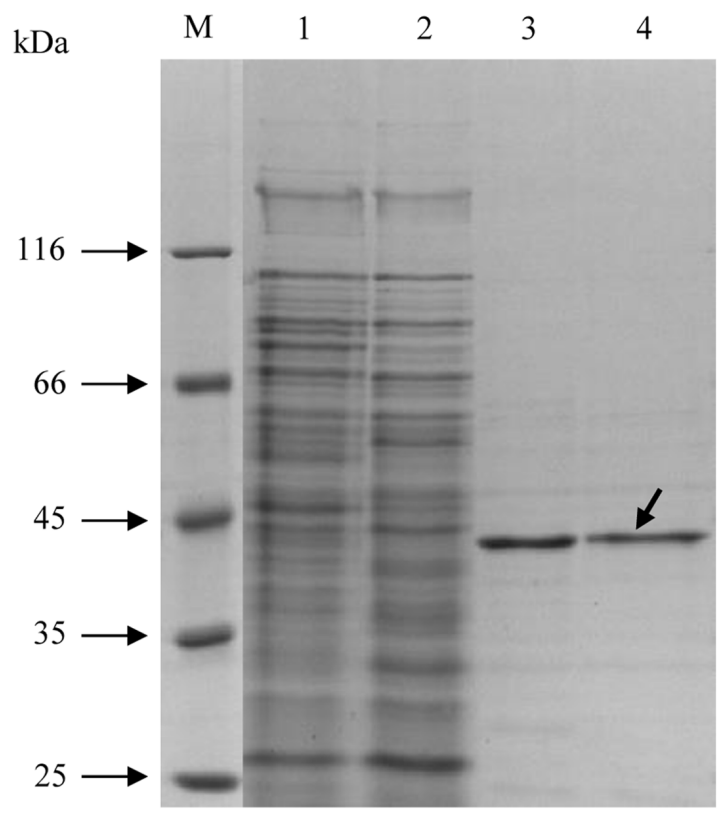

FIGURE 2 | SDS-PAGE (12.5\%) of purification steps of recombinant His-tagged (A) mesaconate CoA-transferase and (B) mesaconyl-CoA hydratase from H. hispanica. M, molecular mass markers; lane 1, cell extract without enzyme activity; lane 2, $H$. volcanii cell extract with measurable activity of the heterologously produced enzyme; lane 3, Ni-sepharose column; lane 4, purified enzyme after gel filtration column. The target proteins are shown with arrows.

respectively, thus suggesting a homodimeric structure for both proteins.

\section{Catalytic Properties of Recombinant Mct}

The purified recombinant Mct catalyzes the transfer of the CoA moiety from succinyl-CoA (CoA donor) to mesaconate (CoA acceptor) (Table 2). Interestingly, only mesaconyl-C1-CoA (and no mesaconyl-C4-CoA) was detected, hence the $\mathrm{C} 1$ - and C4carboxyls can efficiently be distinguished in the active center of the enzyme. High activity was detected with methylsuccinate as CoA-acceptor, and only low activity with glutarate, acrylate and itaconate, whereas no activity was found with methylmalonate, crotonate, acetoacetate, acetate, propionate, butyrate, citrate, $(S)$ and $(R)$-citramalate, 2-hydroxyglutarate, citraconate, fumarate, malate and methacrylate. No activity was found with other CoA donors like acetyl-CoA, propionyl-CoA, butyryl-CoA and acetoacetyl-CoA. Mct did not require divalent ions for activity, and addition of EDTA in the reaction mixture did not inhibit the enzyme (Table 3). The enzyme was dependent on the presence of $\mathrm{KCl}$ and showed highest activity at $4 \mathrm{M} \mathrm{KCl}$ (Figure 3A).

\section{Catalytic Properties of Recombinant Mch}

The purified recombinant Mch catalyzed the hydration of mesaconyl-C1-CoA to (2R,3S)-2-methyl-3-hydroxysuccinyl-C1CoA (erythro- $\beta$-methylmalyl-CoA) (Table 4); the activity was an order of magnitude higher for the reverse reaction ( $\beta$-methylmalyl-CoA dehydration). Notably, a similar ratio of the enzyme activity for forward and reverse reactions was observed in $H$. hispanica and $H$. marismortui cell extracts (Khomyakova et al., 2011; Borjian et al., 2016). The enzyme was also active with mesaconyl-C4-CoA, $(S)$ citramalyl-CoA and (S)-malyl-CoA (Table 4). Nevertheless, enzyme activity was an order of magnitude higher for mesaconylC1-CoA/ $\beta$-methylmalyl-CoA compared to other substrates, thus confirming mesaconyl-C1-CoA and $\beta$-methylmalyl-CoA as its physiological substrates/products. No activity was found 
TABLE 2 | Catalytic properties of the recombinant mesaconate CoA-transferase from $\mathrm{H}$. hispanica.

\begin{tabular}{|c|c|c|c|c|}
\hline \multicolumn{2}{|l|}{ Substrate $^{a}$} & $V_{\max }\left(\mathrm{U} \mathrm{mg}^{-1}\right.$ protein $)$ & $K_{m}(\mathrm{mM})$ & $k_{\text {cat }} / K_{m}\left(\mathrm{~s}^{-1} \mathrm{mM}^{-1}\right)$ \\
\hline \multicolumn{2}{|c|}{ Succinyl-CoA (with 10 mM mesaconate) } & $69.2 \pm 2.6$ & $2.8 \pm 0.2$ & 17.8 \\
\hline \multirow[t]{2}{*}{ Methylsuccinate } & $1 \mathrm{mM}$ succinyl-CoA & $11.0 \pm 0.6$ & $0.6 \pm 0.1$ & 12.4 \\
\hline & 5 mM succinyl-CoA & $36.8 \pm 1.7$ & $2.9 \pm 0.3$ & 9.1 \\
\hline \multirow[t]{2}{*}{ Mesaconate } & $1 \mathrm{mM}$ succinyl-CoA & $17.0 \pm 0.8$ & $1.3 \pm 0.2$ & 9.8 \\
\hline & 5 mM succinyl-CoA & $45.0 \pm 2.1$ & $7.1 \pm 0.8$ & 4.6 \\
\hline Glutarate & $1 \mathrm{mM}$ succinyl-CoA & $18.1 \pm 0.8$ & $40.9 \pm 3.9$ & 0.32 \\
\hline Acrylate & $1 \mathrm{mM}$ succinyl-CoA & $6.2 \pm 0.3$ & $39.3 \pm 4.6$ & 0.12 \\
\hline
\end{tabular}

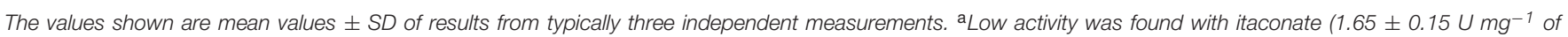

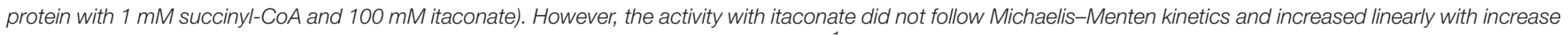

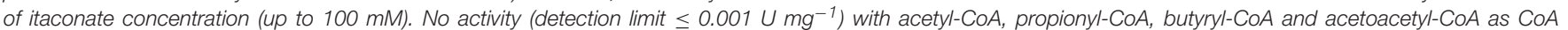

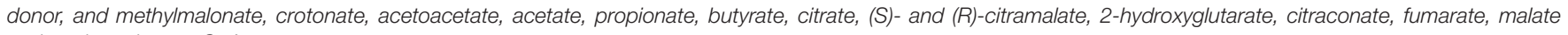
and methacrylate as COA acceptor.

TABLE 3 | Influence of divalent cations on activity of recombinant Mct and Mch from $H$. hispanica.

\begin{tabular}{lcc}
\hline Substrate $^{\mathrm{a}}$ & Mct, \% & Mch, \% \\
\hline No addition $^{\mathrm{b}}$ & $100^{\mathrm{b}}$ & $100^{\mathrm{b}}$ \\
$\mathrm{EDTA}$ & $109 \pm 1$ & $100 \pm 5$ \\
$\mathrm{MgCl}_{2}$ & $93 \pm 1$ & $89 \pm 5$ \\
$\mathrm{MnCl}_{2}$ & $76 \pm 1.5$ & $78 \pm 10$ \\
$\mathrm{NiCl}_{2}$ & $95 \pm 0.5$ & $66 \pm 8$ \\
$\mathrm{CoCl}_{2}$ & $90 \pm 0.2$ & $60 \pm 8$ \\
$\mathrm{CaCl}_{2}$ & $95 \pm 0.1$ & $82 \pm 7$
\end{tabular}

The values shown are mean values $\pm S D$ of results from typically three independent measurements. activity was tested with $1 \mathrm{mM}$ succinyl-COA and $10 \mathrm{mM}$ mesaconate (Mct) or $0.5 \mathrm{mM} \beta$-methylmalyl-CoA (Mch). The concentration of divalent cations was $5 \mathrm{mM}$, EDTA $2 \mathrm{mM}$. ${ }^{\mathrm{b}} 100 \%$ activity corresponds to $15.8 \pm 0.1$ (Mct) and $185 \pm 14$ (Mch) $\cup \mathrm{mg}^{-1}$ of protein.

with itaconyl-C1-CoA, itaconyl-C4-CoA, $(R, S)$-3-hydroxy-3methylglutaryl-CoA and $\beta$-methylcrotonyl-CoA. Mch did not require divalent ions for the activity, and addition of EDTA did not inhibit the enzyme (Table 3). In contrast to Mct, Mch was most active at $0.5 \mathrm{M} \mathrm{KCl}$ (with $82 \%$ of activity at 4 $\mathrm{M} \mathrm{KCl}$ ), whereas the activity dropped severely at $0.1 \mathrm{M} \mathrm{KCl}$ (Figure 3B).

\section{Phylogenetic Analysis of Mct and Mch}

Among haloarchaea sequenced to date, the mct and mch homologs were found only in species that possess the methylaspartate cycle (sequence similarity $\geq 69 / 63 \%$ and $E$-value cutoff $\leq 2 \mathrm{e}-144 / 1 \mathrm{e}-135$, respectively). No homologs with significant sequence similarity were found in other archaea. In the Mct and Mch phylogenetic trees, the haloarchaeal proteins cluster with bacterial proteins (Figure 4). Different archaeal orders (Natrialbales, Haloferacales and Halobacteriales) form separate subclusters in the tree (Figure 4). This indicates that $m c t$ and $m c h$ were (mainly) transmitted vertically among haloarchaea.

Interestingly, haloarchaeal Mch consists of two $(R)$-specific enoyl-CoA hydratase domains. In the Mch phylogenetic tree, most of homologous proteins to the haloarchaeal enzyme possess only one $(R)$-specific enoyl-CoA hydratase domain homologous to the N-terminal domain of the haloarchaeal protein. Homologous bacterial proteins with two $(R)$-specific enoyl-CoA hydratase domains were found only in high GC actinobacteria Tsukamurella pseudospumae, Rhodococcus sp. SC4 (2 sequences), Rhodococcus sp. LB1, Rhodococcus opacus and Pseudonocardia spinosispora. In addition, their genomes contain at least one copy of a gene with sequence highly homologous to Mct, although these putative CoA-transferases are not located in vicinity of the Mch homolog. The genes for other key enzymes of the methylaspartate cycle (e.g., methylaspartate ammonia-lyase and glutamate mutase) are missing in their genomes.

\section{DISCUSSION}

In this work, we characterized a novel member of the class III CoA-transferases (Mct) and a member of the $(R)$-enoyl-CoA hydratases family (Mch). In our previous studies (Khomyakova et al., 2011; Borjian et al., 2016), we proposed that the putative haloarchaeal Mct and Mch function in the methylaspartate cycle for mesaconate activation and subsequent hydration of the produced mesaconyl-C1CoA to $\beta$-methylmalyl-CoA. Our study of the catalytic properties of these enzymes confirmed their preliminary annotation.

The turnover number $k_{\text {cat }}$ of Mct with mesaconate and succinyl-CoA $\left(12.2 \mathrm{~s}^{-1}\right)$ is comparable to the turnover numbers of other characterized class III CoA-transferases, e.g., acetylCoA:oxalate CoA-transferase YfdE from E. coli $\left(22 \mathrm{~s}^{-1}\right)$, succinyl-CoA:(S)-malate CoA-transferase from C. aurantiacus $\left(11.4 \mathrm{~s}^{-1}\right)$, and succinyl-CoA:3-sulfopropionate CoA-transferase from Variovorax paradoxus (37.7 $\mathrm{s}^{-1}$ ) (Friedmann et al., 2006; Schürmann et al., 2013; Mullins et al., 2013). All these CoAtransferases use dicarboxylic acids as substrates. Whereas Mct is highly specific for succinyl-CoA as a CoA-donor, it can activate other carboxylic acids, i.e., methylsuccinate, itaconate, acrylate, and glutarate (Table 2). The activation of these substrates can be considered as a side activity of Mct. Indeed, the $K_{m}$ values for itaconate, glutarate and acrylate were far from the physiological range. Although the catalytic efficiency $k_{\text {cat }} / K_{m}$ for methylsuccinate was even higher than for mesaconate, 

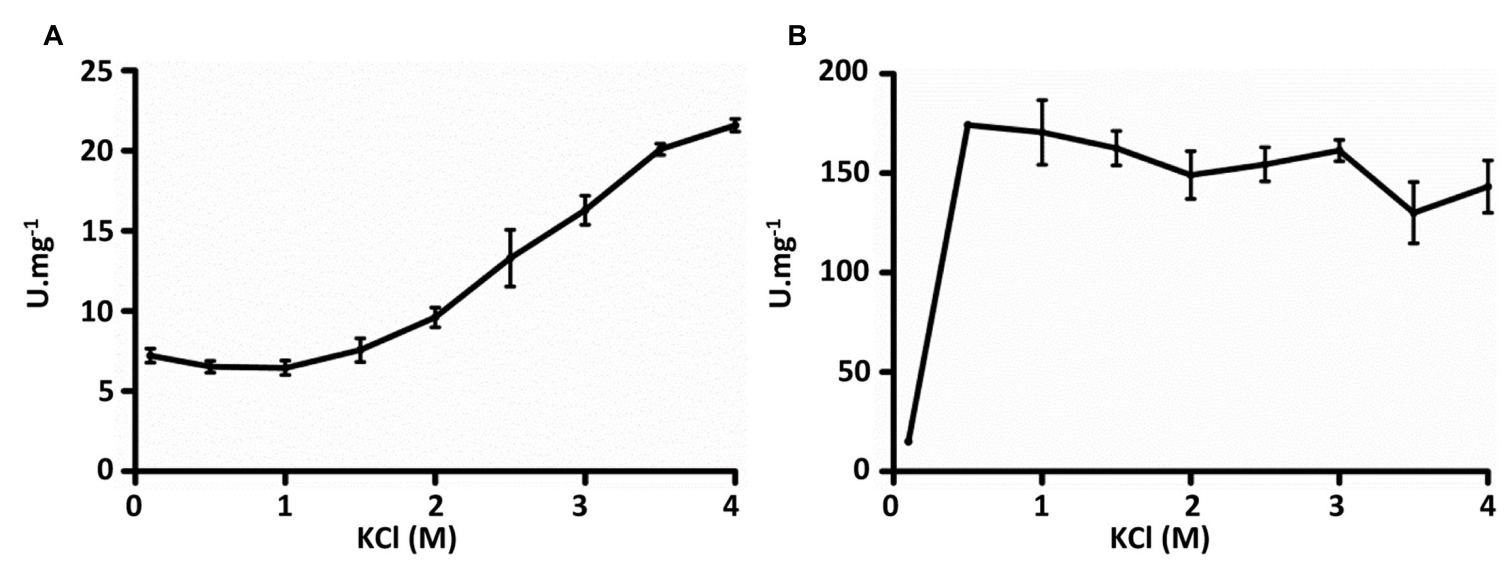

FIGURE 3 | Influence of $\mathrm{KCl}$ on activities of recombinant (A) mesaconate CoA-transferase and (B) mesaconyl-CoA hydratase from $H$. hispanica. Activity was measured with $1 \mathrm{mM}$ succinyl-CoA and $10 \mathrm{mM}$ mesaconate (Mct) and with $0.5 \mathrm{mM} \beta$-methylmalyl-CoA (Mch).

this is probably due to the high structural similarity of mesaconate and methylsuccinate. Methylsuccinate is not a physiological substrate of $H$. hispanica, and its participation in any metabolic pathway in haloarchaea is doubtful. Substrate promiscuity was observed for other members of class III CoAtransferases as well. Succinyl-CoA:(S)-malate CoA-transferase of $C$. aurantiacus also shows high activity with $(S)$-citramalate (Friedmann et al., 2006), and succinyl-CoA:itaconate CoAtransferase from Pseudomonas aeruginosa is highly active with methylsuccinate (Sasikaran et al., 2014). Taken together, the analysis of enzymatic properties of Mct confirms that this protein is a typical member of the class III CoA-transferase superfamily and functions in the methylaspartate cycle for mesaconate activation.

The recognition of three distinct classes of CoA-transferases (EC 2.8.3.x) was based on their structure and catalytic mechanisms (Heider, 2001). Both class I and II enzymes form thioester and anhydride intermediates, although their mechanisms are very different. Class I enzymes function via a ping-pong mechanism and mostly use succinyl-CoA or acetyl-CoA as CoA-donor molecules. Class II enzymes catalyze the transfer of an acyl carrier protein with a covalently bound CoA-derivative. Class III enzymes employ a ternary complex mechanism and use CoA-thioesters, being different from both class I and II enzymes. Nevertheless, the known members of class III are highly different in their quaternary structures. Oxalate CoA-transferase, homodimeric acetyl-CoA:oxalate CoA-transferase (YfdE) and butyrobetainylCoA: $(R)$-carnitine CoA-transferase (CaiB) are monomeric (Baetz and Allison, 1990; Stenmark et al., 2004; Mullins et al., 2013), while benzoylsuccinate CoA-transferase has an $\alpha_{2} \beta_{2}$ structure (Leutwein and Heider, 2001), phenyllactate CoA-transferase forms a complex with phenyllactyl-CoA hydratase (Dickert et al., 2000), and succinyl-CoA:L-malate CoA-transferase has an $(\alpha \beta)_{6}$ structure (Friedmann et al., 2006). Based on size exclusion chromatography data, Mct is a homodimer, like CaiB and YfdE. The amino acid sequence analysis shows $30 / 45 \%$ of identity/similarity to CaiB. Furthermore, most of
TABLE 4 | Catalytic properties of recombinant Mch from H. hispanica.

\begin{tabular}{lccc}
\hline Substrate $^{\mathbf{a}}$ & $\begin{array}{c}\boldsymbol{V}_{\boldsymbol{m a x}}\left(\mathbf{U} \mathbf{~ m g}^{-\mathbf{1}}\right. \\
\text { protein) }\end{array}$ & $\boldsymbol{K}_{\boldsymbol{m}}(\mathbf{m M})$ & $\begin{array}{c}\boldsymbol{k}_{\text {cat }} / \boldsymbol{K}_{\boldsymbol{m}} \\
\mathbf{( s}^{-\mathbf{1}} \mathbf{m M}^{-\mathbf{1}} \mathbf{)}\end{array}$ \\
\hline B-Methylmalyl-COA & $266 \pm 13$ & $0.35 \pm 0.05$ & 254 \\
Mesaconyl-C1-CoA & $20.7 \pm 0.7$ & $1.0 \pm 0.1$ & 6.9 \\
Mesaconyl-C4-CoA & $1.12 \pm 0.02$ & $0.18 \pm 0.01$ & 2.0 \\
(S)-Citramalyl-CoA & $1.6 \pm 0.1$ & $2.6 \pm 0.3$ & 0.2 \\
(S)-Malyl-CoA & $3.6 \pm 0.2$ & $0.32 \pm 0.05$ & 3.8
\end{tabular}

The values shown are mean values $\pm S D$ of results from typically three independent measurements. a Low activity was measured with $1 \mathrm{mM}$ crotonyl-CoA (0.06 U $\mathrm{mg}^{-1}$ ) and $1 \mathrm{mM}$ 3-hydroxybutyryl-CoA $\left(0.034 \mathrm{U} \mathrm{mg}^{-1}\right)$, whereas no activity (detection limit $\leq 0.001 \mathrm{U} \mathrm{mg}^{-1}$ ) was detected with itaconyl-C1-CoA, itaconylC4-CoA, (R, S)-3-hydroxy-3-methylg/utaryl-CoA, $\beta$-methylcrotonyl-CoA.

the residues conserved in CaiB (Stenmark et al., 2004) that were proposed to be important for the folding were also conserved in Mct (Arg16, Gly37, Ala38, Val40, Asp90, Asp169, His185, Thr190, Gly193, but not Leu184; CaiB numbering). Amino acid sequence comparison of Mct with structurally characterized enzymes of class III CoA-transferases shows the highest homology (37/54\% of identity/similarity) to YfdE of E. coli (Figure 5A). Importantly, His233 and its surrounding $\mathrm{GNxH}$ loop in the active center of YfdE are also conserved in Mct (Figure 5B). Therefore, we suggest that Mct belongs to the ACOCT family of class III CoA-transferases superfamily (Mullins et al., 2013).

Mch is the first characterized archaeal enzyme catalyzing mesaconyl-C1-CoA hydration to erythro- $\beta$-methylmalyl-CoA. Two characterized bacterial Mchs function in the ethylmalonylCoA pathway of acetate assimilation ( $R$. sphaeroides) and in the autotrophic 3-hydroxypropionate bi-cycle ( $C$. aurantiacus) (Zarzycki et al., 2008). The equilibrium of Mch is on the side of $\beta$-methylmalyl-CoA, and the catalytic efficiency $k_{c a t} / K_{m}$ for the $\beta$-methylmalyl-CoA dehydration reaction is much higher than for mesaconyl-CoA hydration. However, the physiological direction of the reaction catalyzed by Mch in $H$. hispanica is mesaconyl-CoA hydration, similar to the enzyme functioning 

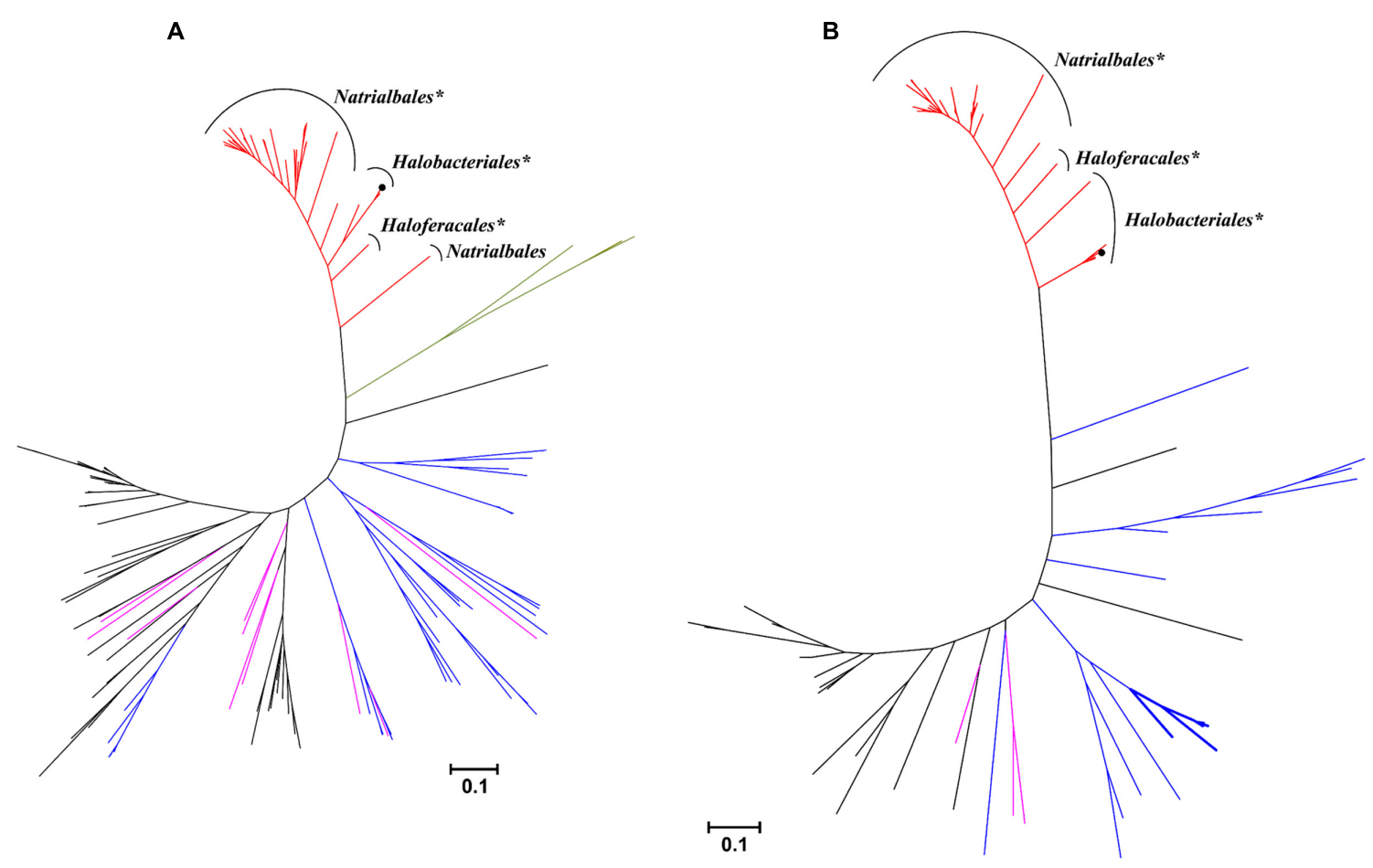

FIGURE 4 | Phylogenetic trees of $H$. hispanica (A) mesaconate CoA-transferase and (B) mesaconyl-CoA hydratase based on amino acid sequence analysis. Standard NCBI BLASTP searches with mesaconate CoA-transferase (Hah_1336) and mesaconyl-CoA hydratase (Hah_1340) from H. hispanica as the queries were performed, and all sequences with $E$-value $\leq 1 \mathrm{e}-100$ for Mct and $\leq 1 \mathrm{e}-20$ for Mch were used for the phylogenetic analysis. Tree topology and evolutionary distances were determined by the maximum-likelihood method with Poisson correction. The scale bar represents a difference of 0.1 substitution per site. The branch colors represent the sequences from haloarchaea, red; $\alpha$-proteobacteria, purple; $\beta$-proteobacteria, black; actinobacteria, blue; Firmicutes, green. The groups marked with asterisk $(*)$ possess the complete set of the methylaspartate cycle genes, the bacterial Mch sequences with two domains are shown in bold lines. Please note that bacterial one-domain sequences were aligned with the $\mathrm{N}$-terminal domain of haloarchael Mch.

in the ethylmalonyl-CoA pathway (Zarzycki et al., 2008). Interestingly, the activity of the haloarchaeal enzyme is an order of magnitude lower than the activities of $R$. sphaeroides and C. aurantiacus enzymes $\left[k_{\text {cat }}\right.$ of $89 s^{-1}$ per dimeric enzyme versus $k_{\text {cat }}$ of $1900 \mathrm{~s}^{-1}$ and $1700 \mathrm{~s}^{-1}$ for the $R$. sphaeroides and C. aurantiacus enzymes, respectively (Zarzycki et al., 2008); Table 4]. It appears that the haloarchaeal enzyme is a less efficient catalyst than the bacterial ones. However, a reliable comparison of these enzymes is not possible, as $K_{m}$ values and substrate specificity of bacterial enzymes are unknown.

Activation of $\mathrm{C} 1$ carboxyl of mesaconate in the Mct reaction is a prerequisite for further production of erythro$\beta$-methylmalyl-CoA in the Mch reaction. erythro- $\beta$-Methylmalyl$\mathrm{CoA}$ can further be cleaved into propionyl-CoA and glyoxylate. Mesaconyl-C4-CoA hydration leads to the formation of (S)citramalyl-CoA, which is cleaved into acetyl-CoA and pyruvate (Zarzycki et al., 2009), whereas hydration of non-activated mesaconate results in the formation of (S)-citramalate. The last reaction is catalyzed by class I fumarases (Kronen and Berg, 2015; Kronen et al., 2015).

Mch catalyzes also mesaconyl-C4-CoA hydration to (S)citramalyl-CoA and fumaryl-CoA hydration to (S)-malylCoA (Table 4). The catalytic efficiency for (S)-malyl-CoA is considerable. Interestingly, this activity could be physiologically relevant, as the $K_{m}$ value for (S)-malyl-CoA is low and $H$. hispanica synthesizes malyl-CoA in its metabolism. Although (to the best of our knowledge) fumaryl-CoA, the product of this reaction, has never being detected as an intermediate in the metabolism, it could further be hydrolyzed to fumarate and $\mathrm{CoA}$, thus forming an alternative route from malyl-CoA to fumarate conversion in the methylaspartate cycle. Although bacterial Mchs have not been tested for malyl-CoA dehydratase activity (Zarzycki et al., 2009), it might be physiologically relevant for the 3-hydroxypropionate bi-cycle. Conversion of succinylCoA to fumaryl-CoA (instead of succinate) via a dehydrogenase and subsequent hydration of fumaryl-CoA to $(S)$-malyl-CoA could save 2 enzymatic steps of the 3-hydroxypropionate bi-cycle. Interestingly, we were able to measure considerable $(\sim 5 \%)(S)$ malyl-CoA dehydratase activity with purified mesaconyl-CoA hydratase from C. aurantiacus (Borjian \& Berg, unpublished), and four copies of putative acyl-CoA dehydrogenases were found in the genome of C. aurantiacus (Tang et al., 2011).

Although haloarchaeal and bacterial enzymes catalyze the same reaction and belong to the same family of $(R)$-specific enoyl-CoA hydratases, it appears that they evolved convergently from different members of this family. Indeed, they are more closely related to other enoyl-CoA hydratases than to each other (Figure 4). While the two mentioned bacterial enzymes 


\section{A}

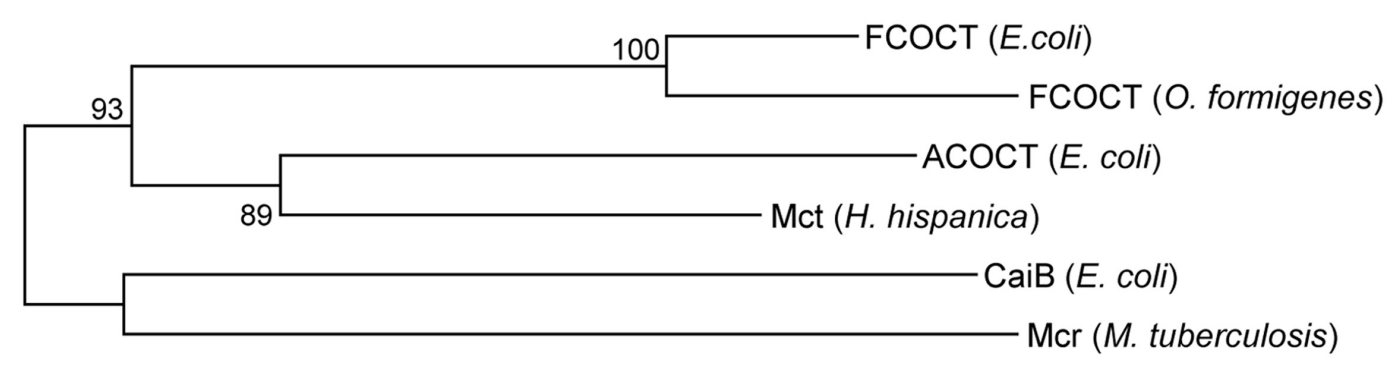

0.2

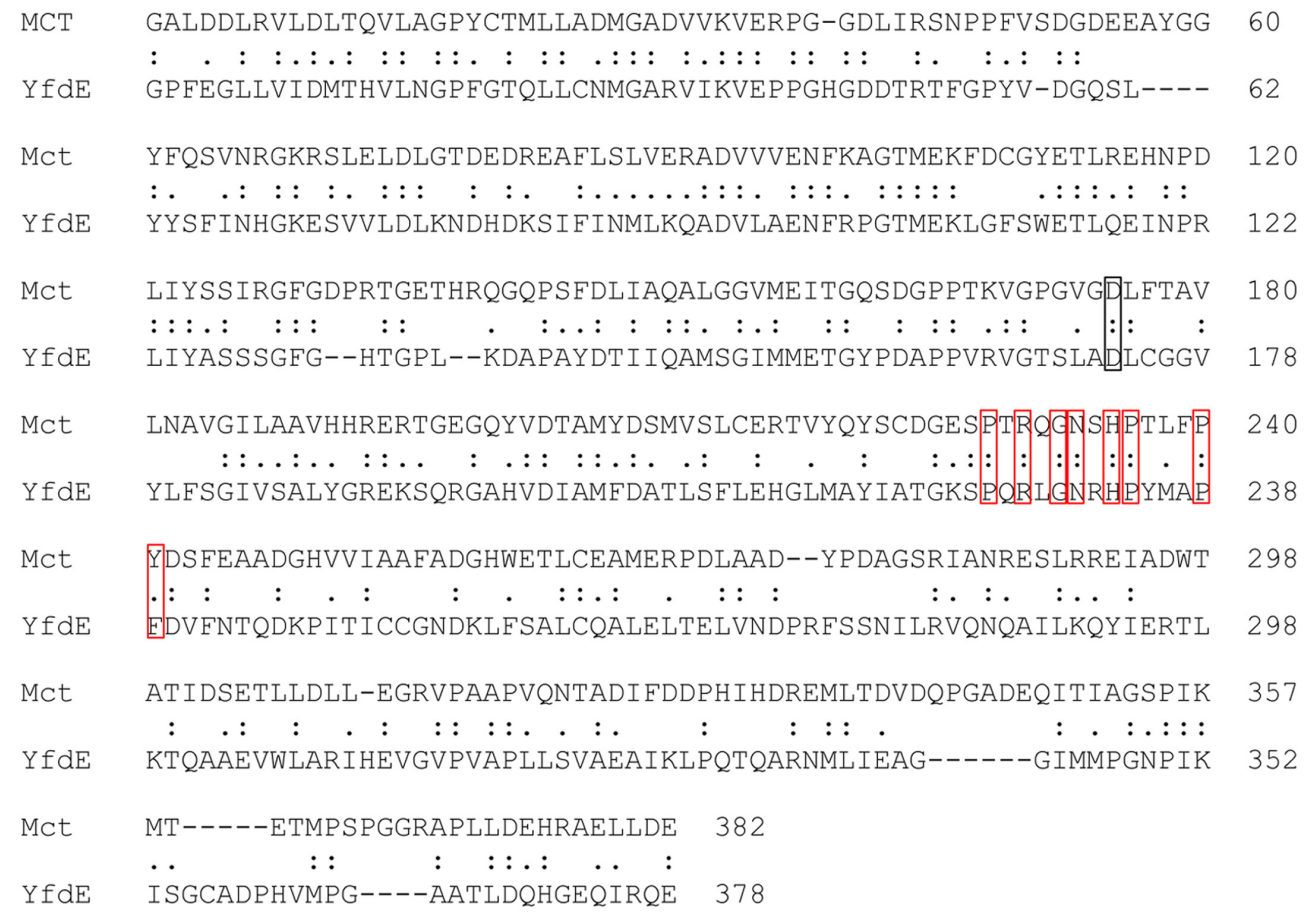

FIGURE 5 | Comparison of H. hispanica Mct with other structurally characterized members of class III CoA-transferases. (A) Phylogenetic tree of the structurally characterized class III CoA-transferases. The tree is based on amino acid sequence analysis. Tree topology and evolutionary distances were calculated using the maximum-likelihood method with Poisson correction. The scale bar represents a difference of 0.2 substitutions per site. Numbers at nodes indicate the percentage bootstrap values for the clade of this group in 1,000 replications. List of the species and accession numbers are given in Supplementary Table S3. (B) Pairwise amino acid sequence comparison of mesaconate CoA-transferase from $\mathrm{H}$. hispanica (Mct) and acetyl-CoA:oxalate CoA transferase from E. coli (YfdE). The black rectangle indicates the catalytically important Asp169 residue and the red ones indicate the conserved GNxH loop.

share a considerable homology $(58 / 73 \%$ of identity/similarity, $E$-value $<\mathrm{e}-141$ ), haloarchaeal Mch seems to be phylogenetically distinct and shows only $26 / 41 \%$ of identity/similarity with an $E$-value of $>5 \mathrm{e}-13$ to the Rhodobacter and $24 / 36 \%$ of identity/similarity with an E-value of $>5 \mathrm{e}-8$ to the Chloroflexus enzymes.

As shown in Figure 3, Mct and Mch show different behavior toward $\mathrm{KCl}$ concentrations. This can be due to the lower theoretical pI of Mct (4.3 for Mct versus 4.7 for Mch), which indicates the presence of higher number of acidic residues on the surface, thus requiring more $\mathrm{KCl}$ molecules for the proper protein folding (Mevarech et al., 2000). This is not surprising, as even a slight difference in amino acid sequence can lead to a dramatic shift in halophilicity of a protein. For example, amino acid sequences of nucleoside phosphate kinases of Haloarcula quadrata and Haloarcula sianaiiensis differ only in one residue but have optimal $\mathrm{KCl}$ concentration $1 \mathrm{M}$ and $2 \mathrm{M}$, respectively (Yamamura et al., 2009). 
Taken together, our results show that haloarchaeal Mct and Mch can be regarded as characteristic enzymes of the methylaspartate cycle. They can easily be recognized in a standard BLASTP search, and their presence seems to indicate the presence of a functional methylaspartate cycle in an organism. Indeed, although Halobacterium salinarum genome encodes the genes for glutamate mutase and methylaspartate ammonia-lyase, Mct and Mch homologues are absent, and the species is not capable to grow with acetate as a sole carbon source (Falb et al., 2008; Borjian et al., 2016).

\section{AUTHOR CONTRIBUTIONS}

IB and PS designed the study. IB and FB wrote the manuscript. FB and UJ performed the experimental work.

\section{REFERENCES}

Allers, T., Barak, S. H., Liddell, S., Wardell, K., and Mevarech, M. (2010). Improved strains and plasmid vectors for conditional overexpression of Histagged proteins in Haloferax volcanii. Appl. Environ. Microbiol. 76, 1759-1769. doi: 10.1128/Aem.02670-09

Altschul, S. F., Gish, W., Miller, W., Myers, E. W., and Lipman, D. J. (1990). Basic local alignment search tool. J. Mol. Biol. 215, 403-410. doi: 10.1016/S00222836(05)80360-2

Andrei, A. Ş., Banciu, H. L., and Oren, A. (2012). Living with salt: metabolic and phylogenetic diversity of archaea inhabiting saline ecosystems. FEMS Microbiol. Lett. 330, 1-9. doi: 10.1111/j.1574-6968.2012.02526.x

Ausubel, F. M., Brent, R., Kingston, R. E., Moore, D. D., Seidman, J. G., Smith, J. A., et al. (1987). Current Protocols in Molecular Biology. New York: John Wiley.

Baetz, A. L., and Allison, M. J. (1990). Purification and characterization of formyl-coenzyme A transferase from Oxalobacter formigenes. J. Bacteriol. 172, 3537-3540. doi: 10.1128/jb.172.7.3537-3540.1990

Borjian, F., Han, J., Hou, J., Xiang, H., and Berg, I. A. (2016). The methylaspartate cycle in haloarchaea and its possible role in carbon metabolism. ISME J. 10, 546-557. doi: 10.1038/ismej.2015.132

Borjian, F., Han, J., Hou, J., Xiang, H., Zarzycki, J., and Berg, I. A. (2017). Malate synthase and $\beta$-methylmalyl coenzyme A lyase reactions in the methylaspartate cycle in Haloarcula hispanica. J. Bacteriol. 199:e00657-16. doi: 10.1128/Jb. 00657-16

Bradford, M. M. (1976). A rapid and sensitive method for the quantification of microgram quantities of protein utilizing the principle of proteindye binding. Anal. Biochem. 72, 248-254. doi: 10.1016/0003-2697(76) 90527-3

Cox, J., and Mann, M. (2008). MaxQuant enables high peptide identification rates, individualized p.p.b.-range mass accuracies and proteome-wide protein quantification. Nat. Biotechnol. 26, 1367-1372. doi: 10.1038/nbt.1511

Dickert, S., Pierik, A. J., Linder, D., and Buckel, W. (2000). The involvement of coenzyme A esters in the dehydration of $(R)$-phenyllactate to $(E)$-cinnamate by Clostridium sporogenes. Eur. J. Biochem. 267, 3874-3884. doi: 10.1046/j.14321327.2000.01427.x

Dym, A., Mavaerech, M., and Sussma, J. L. (1995). Structural features that stabilize halophilic malate dehydrogenase from an archaebacterium. Science 267, 1344-1346. doi: 10.1126/science.267.5202.1344

Falb, M., Müller, K., Königsmaier, L., Oberwinkler, T., Horn, P., von Gronau, S., et al. (2008). Metabolism of halophilic archaea. Extremophiles 12, 177-196. doi: 10.1007/s00792-008-0138-x

Felsenstein, J. (1981). Evolutionary trees from Dna sequences: a maximum likelihood approach. J. Mol. Evol. 17, 368-376. doi: 10.1007/Bf01734359

Friedmann, S., Steindorf, A., Alber, B. E., and Fuchs, G. (2006). Properties of succinyl-coenzyme A:l-malate coenzyme A transferase and its role in the autotrophic 3-hydroxypropionate cycle of Chloroflexus

\section{FUNDING}

This work was funded by the Deutsche Forschungsgemeinschaft (BE 4822/3-1 and Heisenberg Fellowship BE 4822/1-2 to IB).

\section{ACKNOWLEDGMENTS}

The authors thank G. Fuchs (Freiburg) for discussions, suggestions and critical reading of the manuscript.

\section{SUPPLEMENTARY MATERIAL}

The Supplementary Material for this article can be found online at: http://journal.frontiersin.org/article/10.3389/fmicb. 2017.01683/full\#supplementary-material

aurantiacus. J. Bacteriol. 188, 2646-2655. doi: 10.1128/Jb.188.7. 2646-2655

Gill, S. C., and von Hippel, P. H. (1989). Calculation of protein extinction coefficients from amino acid sequence data. Anal. Biochem. 182, 319-326. doi: 10.1016/0003-2697(89)90602-7

Heider, J. (2001). A new family of CoA-transferases. FEBS Lett. 509, 345-349. doi: 10.1016/S0014-5793(01)03178-7

Khomyakova, M., Bükmez, Ö., Thomas, L. K., Erb, T. J., and Berg, I. A. (2011). A methylaspartate cycle in haloarchaea. Science 331, 334-337. doi: 10.1126/ science. 1196544

Kornberg, H. L., and Krebs, H. A. (1957). Synthesis of cell constituents from C2units by a modified tricarboxylic acid cycle. Nature 179, 988-991. doi: 10.1038/ $179988 \mathrm{a} 0$

Kronen, M., and Berg, I. A. (2015). Mesaconase/fumarase FumD in Escherichia coli O157:H7 and promiscuity of Escherichia coli class I fumarases FumA and FumB. PLoS ONE 10:e0145098. doi: 10.1371/journal.pone.0145098

Kronen, M., Sasikaran, J., and Berg, I. A. (2015). Mesaconase activity of class I fumarase contributes to mesaconate utilization by Burkholderia xenovorans. Appl. Environ. Microbiol. 81, 5632-5638. doi: 10.1128/AEM.0082215

Laemmli, U. K. (1970). Cleavage of structural proteins during assembly of the head of bacteriophage T4. Nature 227, 680-685. doi: 10.1038/227680a0

Lanyi, J. K. (1974). Salt-dependent properties of proteins from extremely halophilic bacteria. Bacteriol. Rev. 38, 272-290.

Leutwein, C., and Heider, J. (2001). Succinyl-CoA:(R)-benzylsuccinate CoAtransferase: an enzyme of the anaerobic toluene catabolic pathway in denitrifying bacteria. J. Bacteriol. 183, 4288-4295. doi: 10.1128/JB.183.14.42884295

Mevarech, M., Frolow, F., and Gloss, L. M. (2000). Halophilic enzymes: proteins with a grain of salt. Biophys. Chem. 86, 155-164. doi: 10.1016/S0301-4622(00) 00126-5

Mullins, E. A., Sullivan, K. L., and Kappock, T. J. (2013). Function and X-ray crystal structure of Escherichia coli YfdE. PLoS ONE 8:e67901. doi: 10.1371/journal. pone.0067901

Oren, A. (2002). Halophilic Microorganisms and Their Environments. Dordrecht: Kluwer Academic Publishers. doi: 10.1007/0-306-48053-0

Sambrook, J., Fritsch, E. F., and Maniatis, T. (1989). Molecular Cloning: A Laboratory Manual. New York, NY: Cold Spring Harbor Laboratory Press.

Sasikaran, J., Ziemski, M., Zadora, P. K., Fleig, A., and Berg, I. A. (2014). Bacterial itaconate degradation promotes pathogenicity. Nat. Chem. Biol. 10, 371-377. doi: 10.1038/nchembio.1482

Schürmann, M., Hirsch, B., Wübbeler, J. H., Stöveken, N., and Steinbüchel, A. (2013). Succinyl-CoA:3-sulfinopropionate CoA-transferase from Variovorax paradoxus strain TBEA6, a novel member of the class III coenzyme A (CoA)transferase family. J. Bacteriol. 195, 3761-3773. doi: 10.1128/JB.00456- 13

Serrano, J. A., Camacho, M., and Bonete, M. J. (1998). Operation of glyoxylate cycle in halophilic archaea: presence of malate synthase and isocitrate lyase 
in Haloferax volcanii. FEBS Lett. 434, 13-16. doi: 10.1016/S0014-5793(98) 00911-9

Simon, E. J., and Shemin, D. (1953). The preparation of S-succinyl coenzyme-A. J. Am. Chem. Soc. 75, 2520. doi: 10.1021/ja01106a522

Stadtman, E. R. (1957). Preparation and assay of acyl coenzyme A and other thiol esters; use of hydroxylamine. Methods Enzymol. 3, 931-941. doi: 10.1016/ S0076-6879(57)03481-3

Stenmark, P., Gurmu, D., and Nordlund, P. (2004). Crystal structure of CaiB, a type-III CoA transferase in carnitine metabolism. Biochemistry 43, 13996-14003. doi: 10.1021/bi048481c

Tamura, K., Stecher, G., Peterson, D., Filipski, A., and Kumar, S. (2013). MEGA6: molecular evolutionary genetics analysis version 6.0. Mol. Biol. Evol. 30, 2725-2729. doi: 10.1093/molbev/mst197

Tang, K. H., Barry, K., Chertkov, O., Dalin, E., Han, C. S., Hauser, L. J., et al. (2011). Complete genome sequence of the filamentous anoxygenic phototrophic bacterium Chloroflexus aurantiacus. BMC Genomics 12:334. doi: 10.1186/14712164-12-334

Teufel, R., Gantert, C., Voss, M., Eisenreich, W., Haehnel, W., and Fuchs, G. (2011). Studies on the mechanism of ring hydrolysis in phenylacetate degradation: a metabolic branching point. J. Biol. Chem. 286, 11021-11034. doi: 10.1074/jbc. M110.196667

Thompson, J. D., Higgins, D. G., and Gibson, T. J. (1994). CLUSTAL $\mathrm{W}$ : improving the sensitivity of progressive multiple sequence alignment through sequence weighting, position-specific gap penalties and weight matrix choice. Nucleic Acids Res. 22, 4673-4680. doi: 10.1093/nar/22.22. 4673
Yamamura, A., Ichimura, T., Kamekura, M., Mizuki, T., Usami, R., Makino, T., et al. (2009). Molecular mechanism of distinct salt-dependent enzyme activity of two halophilic nucleoside diphosphate kinases. Biophys. J. 96, 4692-4700. doi: 10.1016/j.bpj.2009.03.012

Zarzycki, J., Brecht, V., Müller, M., and Fuchs, G. (2009). Identifying the missing steps of the autotrophic 3-hydroxypropionate $\mathrm{CO} 2$ fixation cycle in Chloroflexus aurantiacus. Proc. Natl. Acad. Sci. U.S.A. 106, 21317-21322. doi: 10.1073/pnas.0908356106

Zarzycki, J., Schlichting, A., Strychalsky, N., Müller, M., Alber, B. E., and Fuchs, G. (2008). Mesaconyl-coenzyme A hydratase, a new enzyme of two central carbon metabolic pathways in bacteria. J. Bacteriol. 190, 1366-1374. doi: 10.1128/JB. 01621-07

Zehr, B. D., Savin, T. J., and Hall, R. E. (1989). A one-step, low-background coomassie staining procedure for polyacrylamide gels. Anal. Biochem. 182, 157-159. doi: 10.1016/0003-2697(89)90734-3

Conflict of Interest Statement: The authors declare that the research was conducted in the absence of any commercial or financial relationships that could be construed as a potential conflict of interest.

Copyright (C) 2017 Borjian, Johnsen, Schönheit and Berg. This is an open-access article distributed under the terms of the Creative Commons Attribution License (CC BY). The use, distribution or reproduction in other forums is permitted, provided the original author(s) or licensor are credited and that the original publication in this journal is cited, in accordance with accepted academic practice. No use, distribution or reproduction is permitted which does not comply with these terms. 